\title{
Wireless acquisition of multi-channel seismic data using the Seismobile system
}

\author{
Zbigniew Isakow $^{1, *}$ \\ ${ }^{1}$ Institute of Innovative Technologies EMAG, 40-189 Katowice, Poland
}

\begin{abstract}
This paper describes the wireless acquisition of multi-channel seismic data using a specialized mobile system, Seismobile, designed for subsoil diagnostics for transportation routes. The paper presents examples of multi-channel seismic records obtained during system tests in a configuration with 96 channels (4 landstreamers of 24-channel) and various seismic sources. Seismic waves were generated at the same point using different sources: a 5-kg hammer, a Gisco's source with a 90-kg pile-driver, and two other the pile-drivers of 45 and $70 \mathrm{~kg}$. Particular attention is paid to the synchronization of source timing, the measurement of geometry by autonomous GPS systems, and the repeatability of triggering measurements constrained by an accelerometer identifying the seismic waveform. The tests were designed to the registration, reliability, and range of the wireless transmission of survey signals. The effectiveness of the automatic numbering of measuring modules was tested as the system components were arranged and fixed to the streamers. After measurements were completed, the accuracy and speed of data downloading from the internal memory (SDHC 32GB WiFi) was determined. Additionally, the functionality of automatic battery recharging, the maximum survey duration, and the reliability of battery discharge signalling were assessed.
\end{abstract}

\section{Introduction}

Geophysical methods have been demonstrated to be effective tools in imaging the shallow subsurface beneath transport routes and assessing mechanisms of subsurface deformation [18]. Many studies have investigated these methods. Among the various geophysical methods, the most applicable for designing new transport routes and rehabilitating existing ones are GPR, seismics, and electrical resistivity [8]. In this context, the geological and engineering conditions of the shallow subsurface are analysed to identify structurally weak zones. Weak zones are identified on the basis of variations in the physical properties of the medium, zones of irregular groundwater flow (including leaching zones), changes in the ground water level caused by drainage or irrigation infrastructure, organic soil and quick-sands, landslide zones, tectonics, the occurrence of voids and fractures due to mining and karst areas [8-10].

Interest in mobile landstreamer seismic systems has increased in recent years $[8,11]$. The Seismobile system was developed by combining seismic landstreamers and GPR profiling $[8,12]$. The Seismobile system enables wireless geophysical subsurface profiling, including

*Corresponding author: z.isakow@ibemag.pl 
refraction, reflection, MASW (Multi-channel Analysis of Surface Waves), and GPR. The main system component is the seismic landstreamer, which permits faster seismic measurements under conditions difficult for geophone mounting, such as concrete or asphalt road surfaces. The Seismobile landstreamer is a mobile construct that enables $1-4$ woven belts to be towed with a total of 96 geophones with the accompanying modules for survey geometry measurement. More information regarding the Seismobile system can be found in $[8,11-15]$.

The known methods and systems for survey data collection, discussed in [11], are based on an array of streamers with electrodynamic geophones, accelerometers, or mems connected by wired analogue transmission to multi-channel (usually 24 channel) loggers transported on a moving vehicle used as a platform for translocation of the streamers. The use of analogue transmission with large measuring sets (up to 100 sensors) hampers efforts to obtain dynamic recording, due to the potential for electromagnetic interference, which is important when recording weak seismic signals. The cable connections of traditional seismic systems are exposed to damage, and the equipment require time-consuming cables coupling. The Seismobile system eliminates these inconveniences and reduces the time required for system setup by providing a wireless data acquisition platform that eliminates the need for the wired analogue transmission of sensor signals. Brodic et al. [16] have developed an innovative landstreamer system based on 3C MEMS (Micro-Electro-Mechanical System) accelerometers combined with wireless units that are GPS time stamped with nanosecond accuracy. Moreover, the broadband (theoretically 0-800 Hz) MEMS-based sensors enable high-resolution imaging.

The Seismobile system digitally measures data that are recorded on the system's internal Flash memory, while radio transmission is used to configure and control the status of system components, impacting the accuracy of the recording time base synchronization and the initial validation of seismic recording.

\section{Structure, specifications, and operation of the system and its components}

The schematic of the 3D version of the Seismobile system is shown in Figure 1. The construction of the Seismobile system permits towing of up to four measuring lines with geophones and the GPR antenna. The seismic and GPR control units are placed on a vehicle and work independently. The positions of the seismic detectors and the GPR antennas are synchronized by GPS.

The main part of the system is comprised of four measuring landstreamer belts, with each measuring approximately $100 \mathrm{~m}$ long, that enable a maximum of 96 uni- or tri-axial geophone sensors (5). Each sensor works with a measuring module (6) that samples the signal from the sensor and performs the analogue to digital conversion with a dynamic range of $130 \mathrm{~dB}$ and a resolution of 32 bits. Sampling is executed precisely by synchronizing the clocks in the modules (6) with the GPS receivers. The clock within the triggering measurements module (10), assisted by the accelerometer sensor (11) that identifies a moment of the seismic wave excitation, is synchronized with its GPS receiver (12). The synchronous operation of the measuring modules (6) and the control module (10) permits precise time-based synchronization during the digital recording of seismic waves produced by a pile driver source or a hammer. The waveforms (5) recorded in the internal memory of the modules (6) after each wave excitation (7) are wirelessly transmitted to the central processing unit (14), where they are visualized and verified. After each wave excitation, the coordinates of the pile driver and the acceleration of the induced waveform are recorded in the module (10), while the waveforms of the landstreamer sensors (6) are recorded in the memory of a separate set of modules (6). The landstreamer modules (6) are automatically numbered as they are 
fastened to the bases on the landstreamer belts, which are associated with the coordinates from the GPS receiver installed on the ST vehicle and provide unambiguous spatial geometry for the sensor deployment. After survey acquisition, the MP measurement modules are placed in the docking station SD, where their batteries are charged, and the data are downloaded via WiFi. More details on the construction of system components are provided in [13, 14]. An example of the seismic acquisition parameters is presented in Table 1.

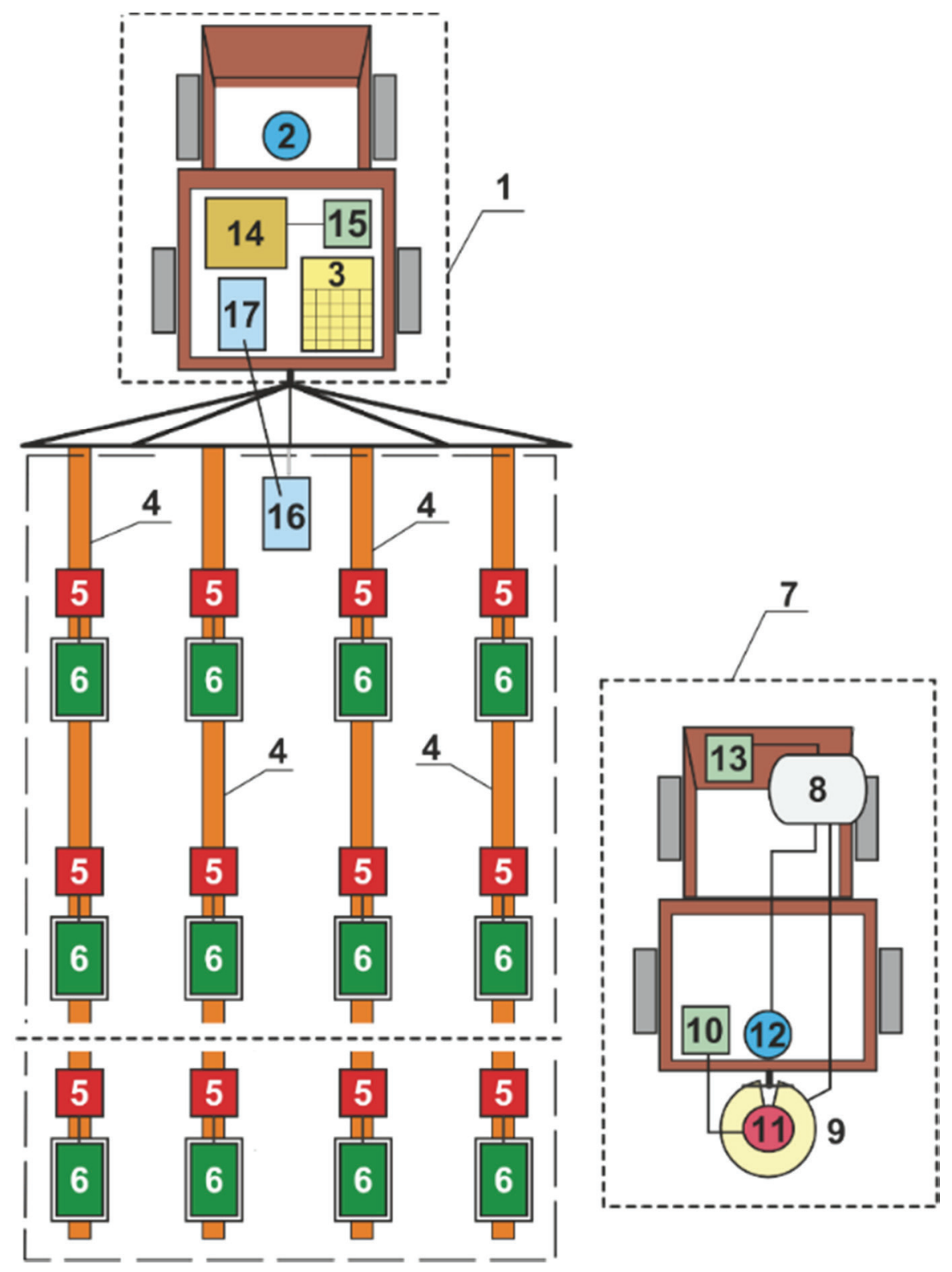

Fig. 1. Basic components of the Seismobile system: 1 - towing vehicle, 2 - GPR receiver, 3 docking station, 4 - woven belt, 5 - seismic sensor (typically 1C or 3C geophone), 6 - measuring module, 7 - mobile weight drop, 8 - weight drop control unit, 9 - pile driver, 10 - measuring module, 11 - accelerometer, 12 - GPS receiver, 13 - radio modem, 14 - database server, 15 - Wi-fi module, 16 - GPR antenna, 17 - GPR control unit, (on the basis of Isakow et al.[15]). 
Table 1. Parameters of seismic acquisition used in tests [8].

\begin{tabular}{|l|l|}
\hline Parameter & Value/description \\
\hline Geophone natural frequency & $10 \mathrm{~Hz}$ \\
\hline Sampling period & $0.125-0.250 \mathrm{msec}$ \\
\hline Seismic record length & $500-1500 \mathrm{msec}$ \\
\hline File format & SEGY \\
\hline Source type & $\begin{array}{l}\text { electrodynamic Gisco ESS200 weight drop }(90 \mathrm{~kg}) \\
\text { and hammer impact }(5 \mathrm{~kg})\end{array}$ \\
\hline Stacking & 8 \\
\hline Distance between landstreamer lines & $2-3.5 \mathrm{~m}$ \\
\hline Geophone intervals & $1-5 \mathrm{~m}$ \\
\hline
\end{tabular}

\section{Testing wireless data acquisition}

During Seismobile testing, multichannel seismic recording comparisons were obtained using a configuration of 80 channels (4 landstreamer 24-channel belts, each filled with 20 measuring modules) with different seismic sources, including a traditional 5-kg hammer, a 90-kg Gisco pile driver, and a custom-made $45-\mathrm{kg}$ pile driver fixed to a special mini KAWASAKI technical car. Figure 2 shows the preparation of the Seismobile measuring set for testing, and Figure 3 shows the entire test track.

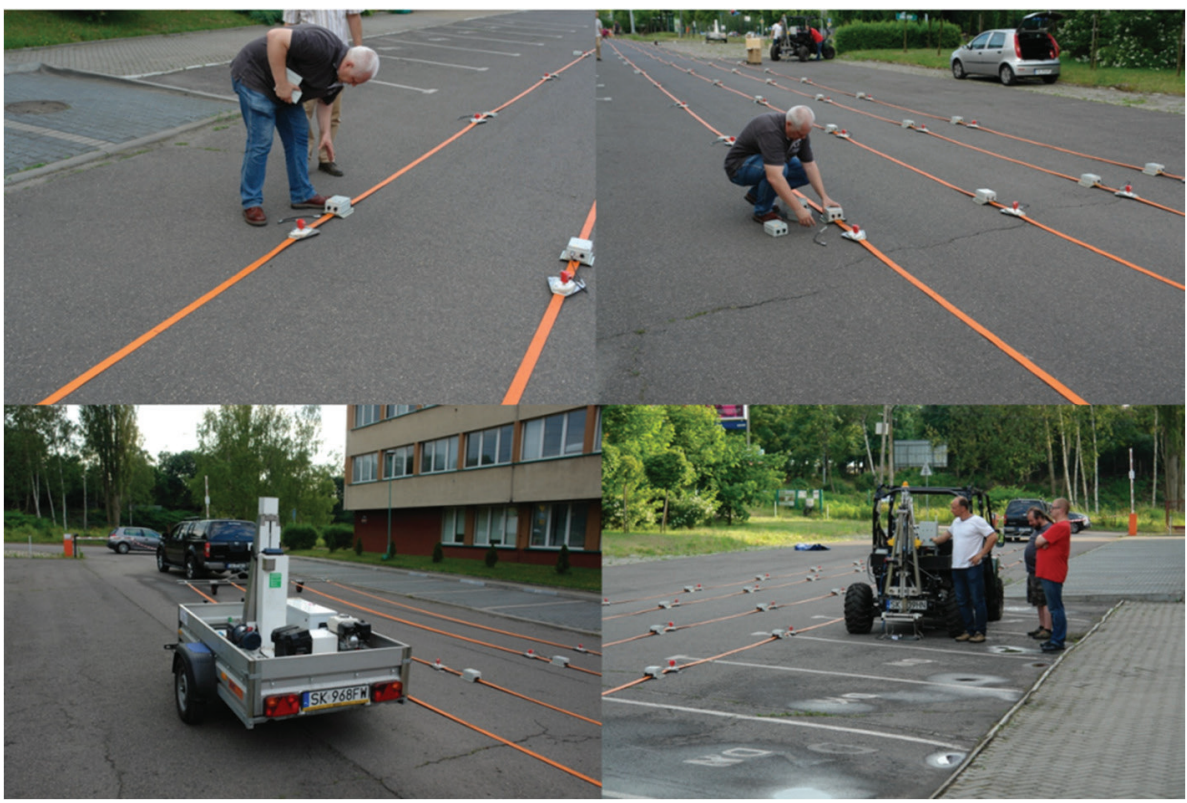

Fig. 2. Preparation of the measuring set for Seismobile testing (assembly of sensors and measuring modules on the tape of S4 streamer), and excitation of a seismic wave signal using the 90-kg piledriver (trailer) and the 45-kg pile-driver mounted to the KAWASAKI mini car.

Figure 4 shows examples of seismic records obtained during wireless data acquisition testing of the Seismobile system. Figure 5 shows sample tests with a summation of results, and Figure 6 compares the frequency range (average spectrum of 10 strokes) of the waves from a 5-kg hammer and 45-kg and 90-kg pile drivers at a distance of $1 \mathrm{~m}$ from sensor no.11 (the sensor located in the middle of the landstreamer belt). 


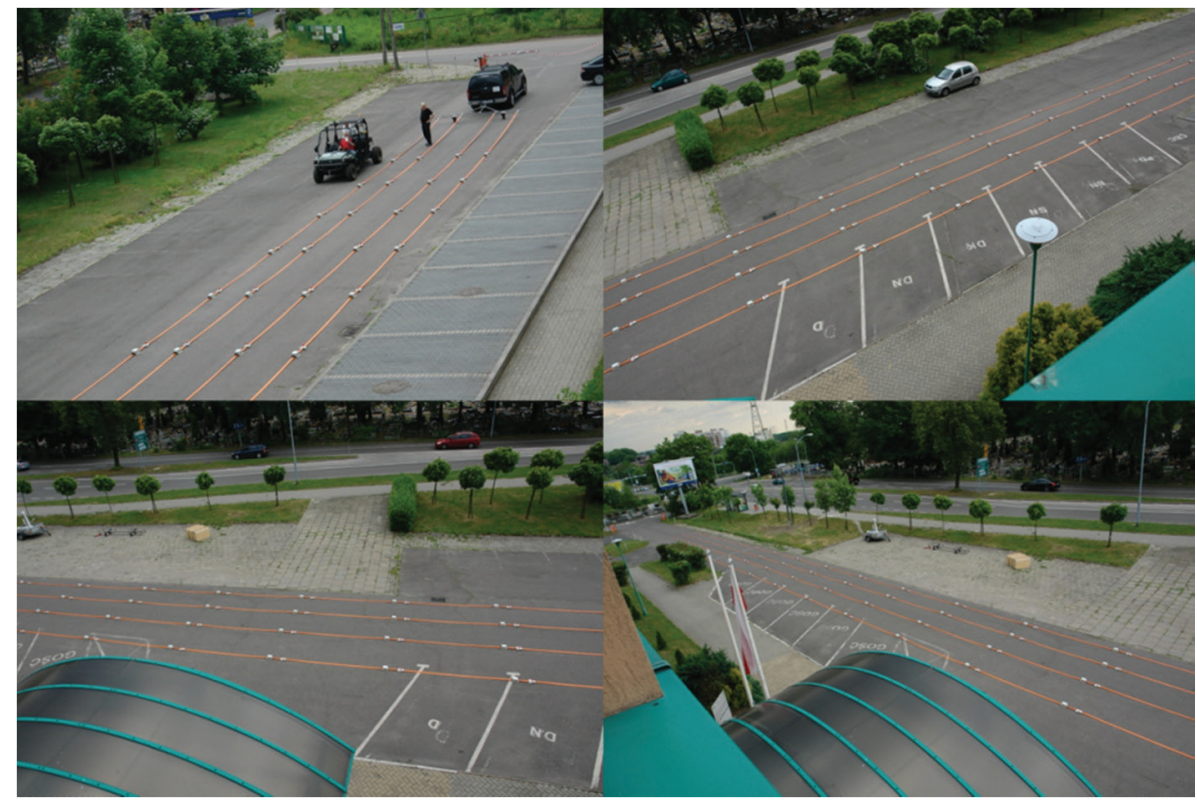

Fig. 3. Set of four streamers belts, $100 \mathrm{~m}$ long, with different spacing (S1-S2 $1 \mathrm{~m}, \mathrm{~S} 2-\mathrm{S} 31.5 \mathrm{~m}, \mathrm{~S} 3-$ S4 $1 \mathrm{~m}$ ), each equipped with $20 \mathrm{GS}-11 \mathrm{D}$ sensors spaced $4 \mathrm{~m}$ apart.

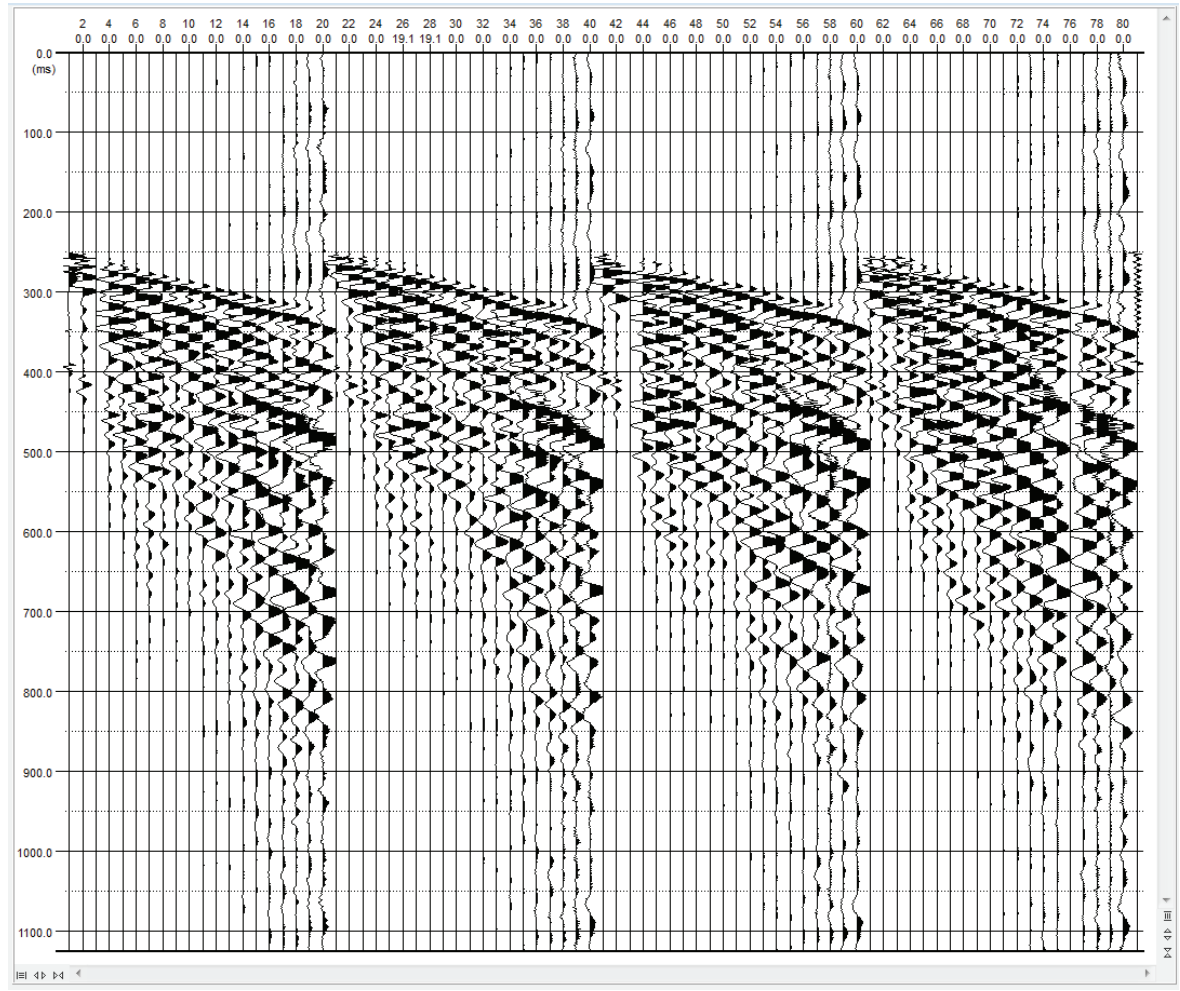

Fig. 4. Examples of wireless seismic recordings registered by the system during testing (45-kg piledriver source, all sensors on tapes of the streamers, excitation at geophone no. 1). 
During the study, particular attention was paid to the synchronization of source timing, the measurement of geometry by autonomous GPS systems, and the repeatability of triggering measurements constrained by an accelerometer identifying the seismic waveform. The dynamics of system registration, the reliability of wireless transmission, and transmission range were also examined. The automatic numbering of the measurement modules was tested as they were laid out and fixed to the landstreamer belts. At the end of the measurement session, the accuracy and speed of data downloading from the internal memory (SDHC 32GB WiFi) of the measurement modules located in the docking station were checked. The functionality of automatic module battery charging when docked, the operating life after battery charging, and the correct signalling of module discharge state were evaluated, as well.

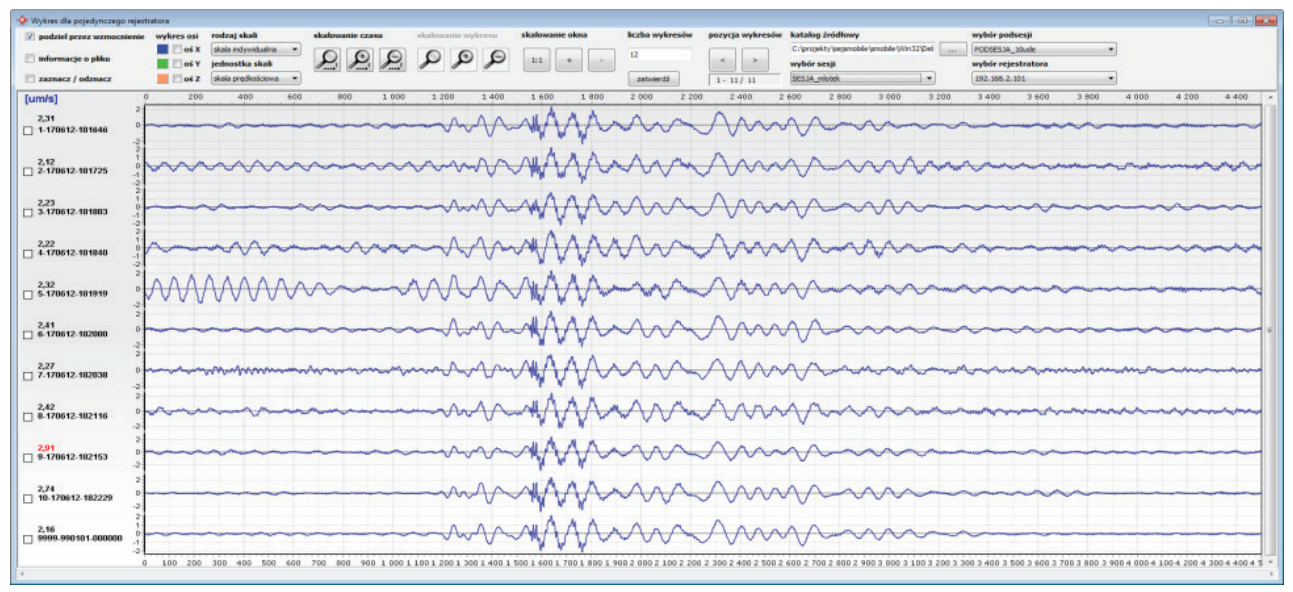

Fig. 5. Example of summing up of 10 recordings excited with a hammer of 5-kg mass for the sensor no. 11 . The top 10 graphs show the components of the sum, while the latest waveform shows the averaging result.

\section{Conclusions}

The Seismobile system tests demonstrate the suitability of the system for field trials. Direct digital recording using internal Flash memory, and the high dynamics of A/D processing provide high quality data, undisturbed by the influence of external magnetic fields. Wireless viewing of seismic records during data acquisition enables a quick assessment of the measured data, while the transmission range is sufficient for measuring at a distance of 100 $\mathrm{m}$. Wireless data logging in Flash memory modules at the end of data acquisition during battery charging ensures reliable archiving of survey data.

The use of uni- and tri-axial sensors ensures the best (in terms of frequency spectrum, amplitude attenuation, and mechanical resonance minimization) transmission of vibrations from the ground. Studies have shown that compared to a $90-\mathrm{kg}$ pile driver, a $45-\mathrm{kg}$ pile driver delivers approximately 30\% less energy to the subsurface, and a 5-kg hammer delivers approximately $80 \%$ less. Demonstrated repeatability of summation of the recorded components without the "trembling" of the signal phase enables the results to be summed effectively.

The 90-kg pile driver generated the lowest frequencies, and the $45-\mathrm{kg}$ pile driver generated more energy at higher frequencies (primarily due to the use of a steel intermediate plate). Fully charged MP modules can work continuously for at least 8 hours, and the charging time of fully discharged battery modules does not exceed 2 hours. 

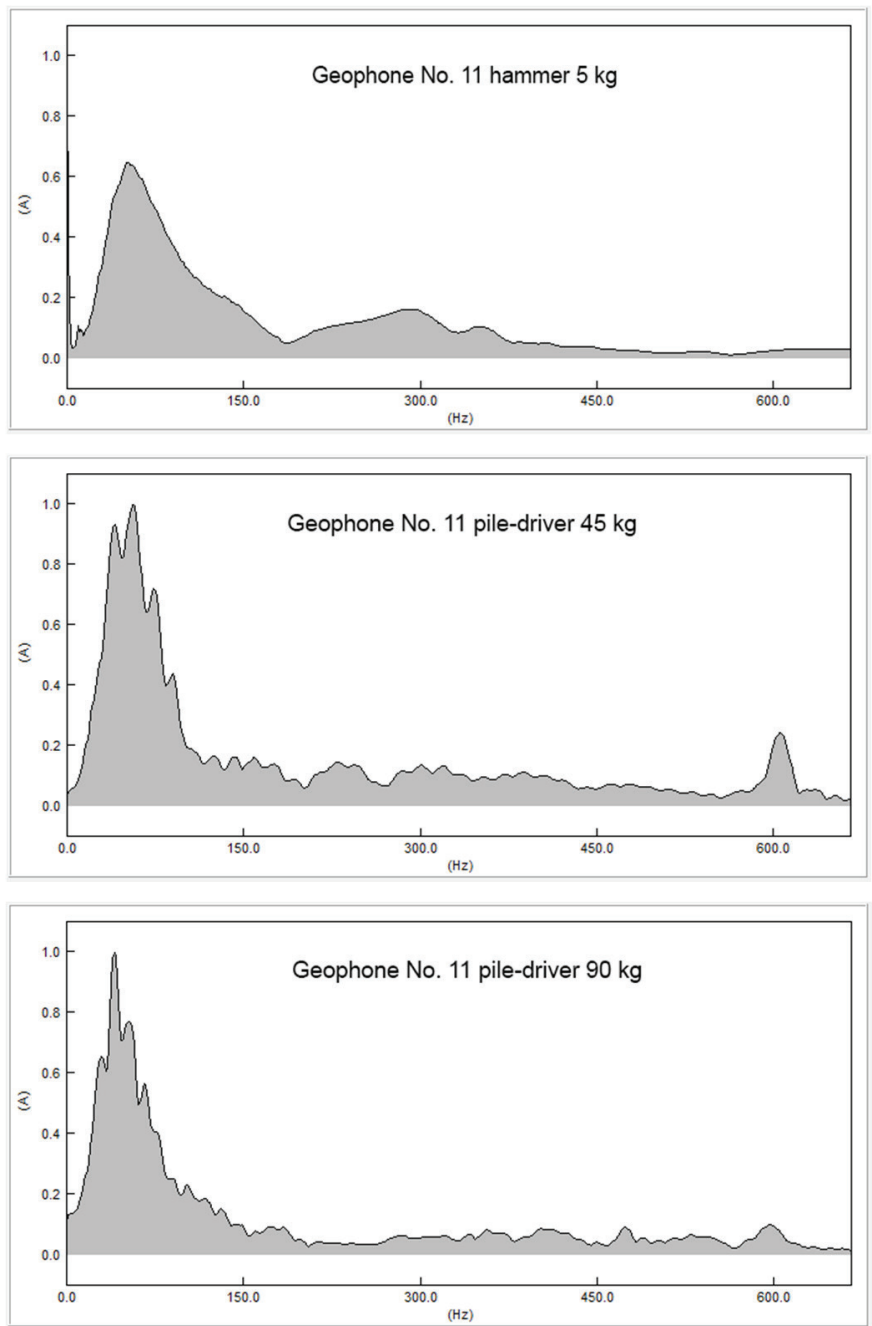

Fig. 6. Comparison of the frequency range (averaged spectrum of 10 strokes) of the excited wave using a 5-kg hammer and the 45-kg and 90-kg pile-drivers at 1 metre distance from sensor no. 11 .

The article was prepared as a result of the SEISMOBILE project No. UOD-DEM-1-303/001 performed within the Applied Research Programme DEMONSTRATOR+ co-financed by the Polish National Centre for Research and Development.

\section{References}

1. J. Hugenschmidt, J. Appl. Geophys. 43, 2-4, 147-155, (2000) doi 10.1016/S09269851(99)00054-3

2. T. Inazaki, Explor. Geophys. 35, 1-6 (2004) doi 10.1071/ EG04001

3. R.D. Miller, High-resolution seismic reflection to identify areas with subsidence potential beneath U.S. 50 highway in Eastern Reno County, Kansas. Proc. Symposium on the Application of Geophysics to Engineering and Environmental Problems 2006, 460-472 (2006) 
4. Z. Pilecki, The role of geophysical methods in the estimation of sinkhole threat in the post-mining areas of shallow exploitation in the Upper Silesian Coal Basin, Poland Gospod. Surowcami Min. 24, 3/1, 27-40 (2008)

5. Z. Pilecki, Methodology for A-1 motorway basement treatment effectiveness improvement by means of geophysical mrthods in the areas of metal ores shallow mining threatened with the sinkhole occurence in the Upper Silesia, Gospod. Surowcami Min. 25, 3, 319-331 (2009)

6. A. Miłkowski, Z. Pilecki, K. Kłosek, M. Tondera, Autostrada Al zaprojektowana na ,,dziurawym” podtożu, Cz. 1, Magazyn Autostrady: Budownictwo Drogowo-Mostowe 3, 104-112 (2010)

7. C. Krawczyk, U. Polom, S. Trabs, T. Dahm, J. Appl. Geophys. 78, 133-143 (2012) dx.doi.org/10.1016/j.jappgeo.2011.02.003

8. Z. Pilecki, Z. Isakow, R. Czarny, E. Pilecka, P. Harba, M. Barnaś, J. Appl. Geophys. 143, 31-41 (2017) doi 10.1016/j.jappgeo.2017.05.016

9. P. Harba, Z. Pilecki, Landslides 14, 1225-1233 (2016) doi 10.1007/s10346-016-0779-2

10. Z. Pilecki, J. Kłosiński, E. Pilecka, J. Karczewski, J. Ziętek, Wpływ zawodnienia osuwiska na rozpoznanie granic jego nieciagłości metodami falowymi, Gospod. Surowcami. Min. 24, 2/3, 427-444 (2008)

11. Z. Pilecki, P. Harba, M. Laszczak, A. Adamczyk, S. Cielesta, Strimery w sejsmice inżynierskiej, Przegląd Górniczy 7, 32-38 (2014)

12. A. Kubańska, Z. Isakow, Z. Pilecki, Założenia funkcjonalne systemu Seismobile, Zeszyty Naukowe - Bulletin of the Mineral and Energy Economy Research Institute of the Polish Academy of Sciences 93, 133-142 (2016)

13. Z. Pilecki, Z. Isakow, A. Kubańska (eds.), Seismobile - system geofizycznego badania podłoża szlaków komunikacyjnych (Bater Drukarnia MY-HORYZONT, Katowice, 2016)

14. Z. Isakow, K. Siciński, P. Sierodzki, Innovative solutions for data acquisition in Seismobile landstreamer, Zeszyty Naukowe - Bulletin of the Mineral and Energy Economy Research Institute of the Polish Academy of Sciences 93, 155-168 (in Polish) (2016)

15. Z. Pilecki, R. Czarny, M. Chamarczuk, K. Krawiec, E. Pilecka, Skuteczność rejestracji zestawu pomiarowego strimera sejsmicznego Seismobile, Zeszyty Naukowe - Bulletin of the Mineral and Energy Economy Research Institute of the Polish Academy of Sciences 93, 143-154 (in Polish) (2016)

16. A. Malehmir, B. Brodic, M. Dehghannejad, C. Juhlin, E. Lundberg, A state-of the-art mems-based 3c seismic landstreamer for various near-surface applications, Proc. 78th EAGE Conference \& Exhibition - Workshop Programme, Vienna, 20 May - 2 June 2016, WS04 B02 (2016) 